Check for updates

Cite this: RSC Adv., 2019, 9, 18918

Received 23rd May 2019

Accepted 10th June 2019

DOI: $10.1039 / c 9 r a 03880 a$

rsc.li/rsc-advances

\section{Copper-catalysed enantioselective intramolecular etherification of propargylic esters: synthetic approach to chiral isochromans $\dagger$}

\author{
Shiyao Liu, ${ }^{a}$ Kazunari Nakajima (D) ${ }^{b}$ and Yoshiaki Nishibayashi (iD) *a
}

Enantioselective synthesis of chiral isochromans bearing a terminal alkyne moiety has been accomplished by copper-catalysed enantioselective intramolecular propargylic substitution reactions of propargylic esters with alcoholic nucleophiles. This method represents the first successful example which directly introduced a terminal alkyne group into chiral isochromans.
Optically active isochromans, a type of oxygen-containing heterocycle, are ubiquitous structures in many natural and synthetic bioactive products, and are also well-known as pharmaceutical and agrochemical candidate compounds (Fig. 1). ${ }^{1,2}$ Although the classical methods such as diastereoselective cyclisation or optical resolution of racemates can furnish the synthesis of optically active isochromans, the limitation of the scope of substrates and the complexity of the synthetic routes delayed the progress of the synthesis of optically active isochromans. ${ }^{3}$ Recently, rapidly emerging methodologies for constructing chiral isochromans by applying asymmetric catalysts are increasingly attracting attention. Typically, two kinds of strategies are listed for providing chiral isochromans by asymmetric catalysis, where one is the enantioselective $\mathrm{C}-\mathrm{C}$ bond formation (Fig. 2a) and the other is the enantioselective $\mathrm{C}-\mathrm{O}$ bond formation (Fig. 2b). In 2008, Jacobsen and co-workers pioneered enantioselective thiourea-catalysed addition of silyl ketene acetals to racemic chloroisochromans. ${ }^{4}$ This group reported a brand-new strategy, where carbon nucleophiles enantioselectively attack the in situ generated oxocarbenium ion intermediates. ${ }^{5}$ Since then, according to the same strategy, some research groups ${ }^{6-8}$ have reported the enantioselective synthesis of chiral $\alpha$-substituted isochromans using other carbon nucleophiles.

On the other hand, reports of the synthesis of chiral isochromans via enantioselective $\mathrm{C}-\mathrm{O}$ bond formation, ${ }^{9}$ where alcohols enantioselectively attack the electrophile moieties, are very scarce. To date, only two research groups found the synthesis of chiral isochromans according to the allylic

\footnotetext{
${ }^{a}$ Department of Systems Innovation, School of Engineering, The University of Tokyo, Hongo, Bunkyo-ku, Tokyo, 113-8656, Japan. E-mail: ynishiba@sys.t.u-tokyo.ac.jp

${ }^{b}$ Frontier Research Centre for Energy and Resources, School of Engineering, The University of Tokyo, Hongo, Bunkyo-ku, Tokyo, 113-8656, Japan

$\dagger$ Electronic supplementary information (ESI) available. CCDC 1910939 (S16). For ESI and crystallographic data in CIF or other electronic format see DOI: 10.1039/c9ra03880a
}

substitution reactions with intramolecular alcohols. In 2011, Kitamura and co-workers reported the Ru-catalysed enantioselective intramolecular allylic etherification of allylic alcohols. In 2016, White and co-workers reported the Pd-catalysed allylic etherification of alkenes (Fig. 2b-1). ${ }^{10,11}$

Although several chiral isochroman motifs have been constructed successfully, reactions which directly introduce a terminal alkyne group into chiral isochroman motifs have not yet been achieved until now. The terminal alkyne group is one of the most diversified functional group in organic chemistry and the enantioselective introduction of the terminal alkyne group into compounds represents a considerably tough challenge in synthetic chemistry. ${ }^{12}$ Meanwhile, as a promising method to introduce a terminal alkyne group to substrates, $\mathrm{Cu}$-catalysed enantioselective propargylic substitution reactions have gained considerable attention in recent years. ${ }^{13,14}$ Recently, we have achieved enantioselective intermolecular etherification of propargylic esters with alcohols, ${ }^{15}$ however, successful examples of enantioselective intramolecular etherification of propargylic esters with alcohols has not yet been reported until now. As an extensive study, we have envisaged Cu-catalysed enantioselective intramolecular etherification of propargylic esters with alcohols as a novel synthetic method for chiral isochromans bearing a terminal alkyne moiety (Fig. 2b-2). Herein, preliminary results are described.

We commenced our study by using 1-(2-(2-hydroxyethyl) phenyl)prop-2-yn-1-yl acetate (1a) as a model substrate. We consider that intramolecular cyclisation of 1a may proceed to

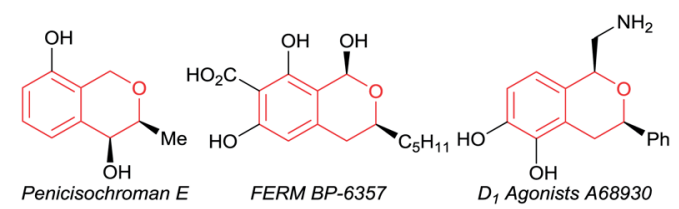

Fig. 1 Bioactive compounds containing optically active isochroman motifs. 
a) Intermolecular Enantioselective C-C Bond Formation

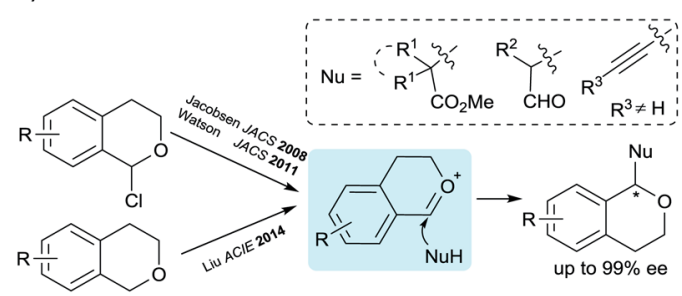

b) Intramolecular Enantioselective C-O Bond Formation

1) Kitamura ACIE 2011, White ACIE 2016

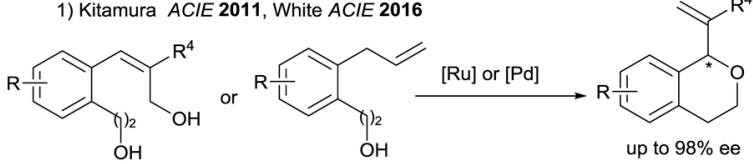

Challenge: No report yet for enantioselective catalytic synthesis of chiral terminal alkynyl isochromans.

2) This work: Copper-Catalysed Intramolecular

Asymmetric Propargylic Substitution Reaction

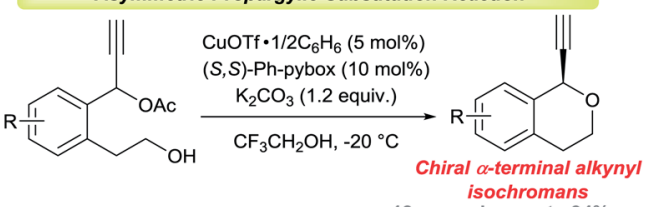

13 examples, up to 94

Fig. 2 Overview of enantioselective synthesis of chiral isochromans and this work.

give the corresponding isochroman (2a) as a desired product. Treatment of $1 \mathrm{a}$ with 1.2 equivalent ${ }_{i{ }_{2}} \mathrm{NEt}$ in the presence of catalytic amounts of CuOTf $\cdot 1 / 2 \mathrm{C}_{6} \mathrm{H}_{6}(5 \mathrm{~mol} \%)$ and various $(S, S)$ pyboxs $(10 \mathrm{~mol} \%)$ as optically active ligands in $\mathrm{MeOH}$ at $25{ }^{\circ} \mathrm{C}$ gave 1-ethynylisochromane (2a) in good yields. At first, we investigated various $(S, S)$-pyboxs such as L1-L5 (Table 1, entries 1-5). In all cases, reactions proceeded smoothly. As a result, the use of $\mathbf{L} \mathbf{5}$ as an optically active ligand gave $2 \mathbf{a}$ with the best enantioselectivity $(65 \%$ ee) (Table 1 , entry 5$)$. When other solvents such as EtOH, iPrOH, and $\mathrm{CF}_{3} \mathrm{CH}_{2} \mathrm{OH}$ were used in place of $\mathrm{MeOH}$ under the same reaction conditions (Table 1, entries 6-8), the highest enantioselectivity ( $88 \%$ ee) was observed in $\mathrm{CF}_{3} \mathrm{CH}_{2} \mathrm{OH}$ as a solvent (Table 1, entry 8 ). The reaction proceeded smoothly even at $-20{ }^{\circ} \mathrm{C}$ to give $2 \mathrm{a}$ with a higher enantioselectivity (90\% ee) (Table 1, entry 9). Unfortunately, the use of other copper salts such as $\mathrm{Cu}\left(\mathrm{NCCH}_{3}\right)_{4} \mathrm{BF}_{4}$, $\mathrm{CuBr} \cdot \mathrm{SMe}_{2}$, and $\mathrm{Cu}(\mathrm{OAc})_{2} \cdot \mathrm{H}_{2} \mathrm{O}$ as catalysts afforded $2 \mathrm{a}$ with a slightly lower enantioselectivity (Table 1, entries 10-12). After fine-tuning of the effect of bases (Table 1, entries 13-15), we found that an inorganic base $\mathrm{K}_{2} \mathrm{CO}_{3}$ worked as the best base in the present reaction system (Table 1, entry 14).

With optimized reaction conditions in hand, we investigated reactions of various $\mathbf{1}$ as substrates. Typical results are shown in Scheme 1. A variety of substituents on the benzene ring of $\mathbf{1}$ are well tolerated for the intramolecular etherification. In fact, reactions of propargylic acetates bearing substituents such as fluoro, trifluoromethyl, methyl, and methoxy groups at the 5-, 6-, and 7positions of the benzene ring gave the corresponding products in good yields with a high enantioselectivity (up to $94 \%$ ee). Unfortunately, introduction of methyl group at the 8-position and chloro group at the 7-position of the benzene ring slightly
Table 1 Optimization of reaction conditions ${ }^{a}$

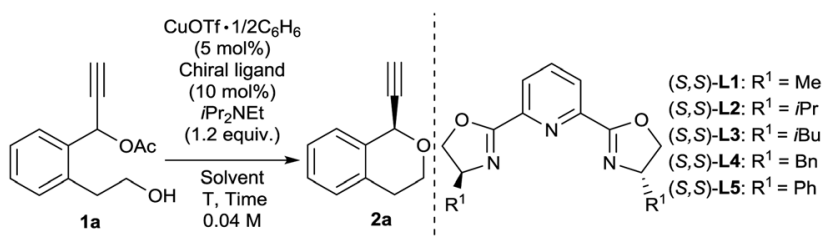

\begin{tabular}{lllrrll} 
Entry & Ligand & Solvent & $T\left({ }^{\circ} \mathrm{C}\right)$ & Time $(\mathrm{h})$ & Yield $^{b}(\%)$ & ee $^{c}(\%)$ \\
\hline 1 & $(S, S)-\mathbf{L 1}$ & $\mathbf{M e O H}$ & 25 & 68 & 82 & 35 \\
2 & $(S, S)-\mathbf{L 2}$ & $\mathbf{M e O H}$ & 25 & 46 & 90 & 58 \\
3 & $(S, S)-\mathbf{L 3}$ & $\mathrm{MeOH}$ & 25 & 47 & 76 & 59 \\
4 & $(S, S)-\mathbf{L 4}$ & $\mathrm{MeOH}$ & 25 & 54 & 85 & 43 \\
5 & $(S, S)-\mathbf{L 5}$ & $\mathrm{MeOH}$ & 25 & 50 & 76 & 65 \\
6 & $(S, S)-\mathbf{L 5}$ & $\mathrm{EtOH}$ & 25 & 41 & 91 & 76 \\
7 & $(S, S)-\mathbf{L 5}$ & $\mathrm{iPrOH}$ & 25 & 43 & 89 & 76 \\
8 & $(S, S)-\mathbf{L 5}$ & $\mathrm{CF}_{3} \mathrm{CH}_{2} \mathrm{OH}$ & 25 & 53 & 88 & 88 \\
9 & $(S, S)-\mathbf{L 5}$ & $\mathrm{CF}_{3} \mathrm{CH}_{2} \mathrm{OH}$ & -20 & 86 & 88 & 90 \\
$10^{d}$ & $(S, S)-\mathbf{L 5}$ & $\mathrm{CF}_{3} \mathrm{CH}_{2} \mathrm{OH}$ & -20 & 112 & 87 & 85 \\
$11^{e}$ & $(S, S)-\mathbf{L 5}$ & $\mathrm{CF}_{3} \mathrm{CH}_{2} \mathrm{OH}$ & -20 & 112 & 80 & 86 \\
$12^{f}$ & $(S, S)-\mathbf{L 5}$ & $\mathrm{CF}_{3} \mathrm{CH}_{2} \mathrm{OH}$ & -20 & 112 & 81 & 88 \\
$13^{g}$ & $(S, S)-\mathbf{L 5}$ & $\mathrm{CF}_{3} \mathrm{CH}_{2} \mathrm{OH}$ & -20 & 52 & 91 & 92 \\
$14^{h}$ & $(S, S)-\mathbf{L 5}$ & $\mathrm{CF}_{3} \mathrm{CH}_{2} \mathrm{OH}$ & -20 & 51 & 89 & 93 \\
$15^{i}$ & $(S, S)-\mathbf{L 5}$ & $\mathrm{CF}_{3} \mathrm{CH}_{2} \mathrm{OH}$ & -20 & 69 & Trace & -
\end{tabular}

a Reaction conditions: 1a $(0.1 \mathrm{mmol})$ with iPr $_{2} \mathrm{NEt}(0.12 \mathrm{mmol}, 1.2$ equiv.) in the presence of copper salt catalyst $(0.005 \mathrm{mmol})$ and chiral ligand $(0.01 \mathrm{mmol})$ in solvent $(2.5 \mathrm{~mL}) .{ }^{b}$ Isolated yield. ${ }^{c}$ Determined by chiral HPLC analysis. ${ }^{d}$ Use $\mathrm{Cu}\left(\mathrm{NCCH}_{3}\right)_{4} \mathrm{BF}_{4}$ as copper salt catalyst. ${ }^{e}$ Use $\mathrm{CuBr} \cdot \mathrm{SMe}_{2}$ as copper salt catalyst. ${ }^{f}$ Use $\mathrm{Cu}(\mathrm{OAc})_{2} \cdot \mathrm{H}_{2} \mathrm{O}$ as copper salt catalyst. ${ }^{g}$ Use $\mathrm{Et}_{3} \mathrm{~N}$ as base. ${ }^{h}$ Use $\mathrm{K}_{2} \mathrm{CO}_{3}$ as base. ${ }^{i}$ Use $\mathrm{NaHCO}_{3}$ as base.

decreased the enantioselectivity. The use of 1-(2-(2-hydroxyethyl) naphthalen-1-yl)prop-2-yn-1-yl acetate $\mathbf{1 m}$ as a substrate under the same reaction conditions gave 1-ethynyl-3,4-dihydro- $1 H^{-}$ benzo[ $h]$ isochromene $2 \mathrm{~m}$ in $57 \%$ yield with $83 \%$ ee. Although we have not yet obtained the exact reason why the use of compounds $1 \mathbf{k}$ and $\mathbf{1 l}$ decreased the lower enantioselectivity, we consider that this is due to the steric hindrance between the substrates and catalyst.

To further investigate the utility of the present reaction, we carried out a larger scale reaction of $1 \mathrm{a}(2 \mathrm{mmol})$. The reaction of $1 \mathrm{a}$ at $-20{ }^{\circ} \mathrm{C}$ for $48 \mathrm{~h}$ gave $2 \mathrm{a}$ in $65 \%$ yield with $90 \%$ ee together with 1a recovered in $23 \%$ (Scheme 2a). Additionally, we investigated further transformation of $2 \mathrm{a}$ because the terminal alkyne moiety in $\mathbf{2 a}$ is a synthetically versatile as a functional group. As typical transformation of terminal alkyne, the Huisgen cycloaddition ${ }^{16}$ and the Sonogashira coupling ${ }^{17}$ of $2 \mathrm{a}$ were carried out (Scheme 2b). To our delight, both catalytic reactions proceeded smoothly to give the corresponding products ( 3 and 4 , respectively) in excellent yields without the loss of the optical purity. To determine the absolute configuration of products 2 , we carried out the Huisgen cycloaddition of chiral isochroman $2 \mathbf{l}$ with benzyl azide to give the corresponding cycloaddition product S16 successfully. After the recrystallisation, we confirmed the absolute configuration of $\mathbf{S 1 6}$ by X-ray diffraction analysis (Fig. S1†). We determined that the absolute 


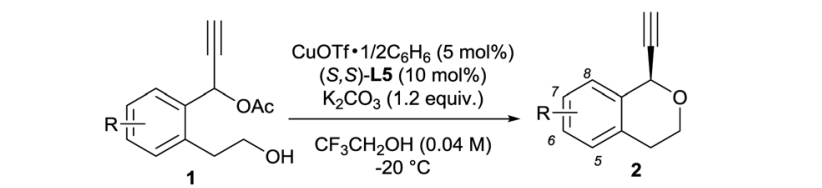

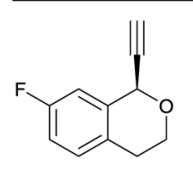

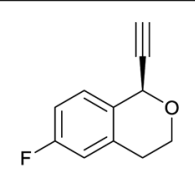

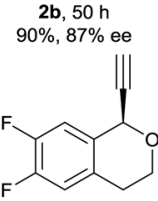
2c, $70 \mathrm{~h}$

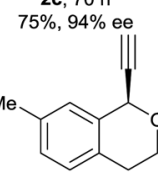<smiles>[114CH3]</smiles>
$51 \%, 92 \%$ ee<smiles>C#CC1OCCc2ccc(OC)cc21</smiles>
2j, $48 \mathrm{~h}$ $72 \%, 93 \%$ ee $75 \%, 88 \%$ ee

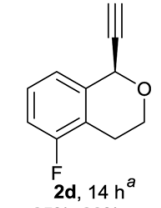
2d, $14 \mathrm{~h}^{\mathrm{a}}$<smiles>Cc1ccc2c(c1)CCO[C@H]2C#C[13CH3]</smiles>

2h, 30 h $90 \%, 91 \%$ ee
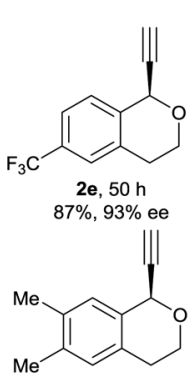

$2 \mathrm{i}, 48 \mathrm{~h}$ $66 \%, 87 \%$ ee

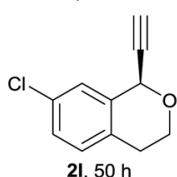

$85 \%, 80 \%$ ee

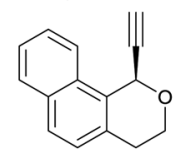

2m, $46 \mathrm{~h}$
Scheme 1 Scope of substrates. Reactions were performed on

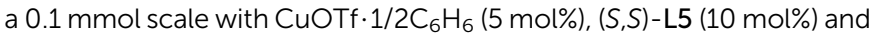
$\mathrm{K}_{2} \mathrm{CO}_{3}$ (1.2 equiv.) in $\mathrm{CF}_{3} \mathrm{CH}_{2} \mathrm{OH}(2.5 \mathrm{~mL})$ at $-20^{\circ} \mathrm{C}$. Yields are for the isolated products. The ee values were determined by chiral HPLC analysis. ${ }^{\mathrm{a}} 1 \mathrm{~d}(0.3 \mathrm{mmol}), \mathrm{CF}_{3} \mathrm{CH}_{2} \mathrm{OH}(5 \mathrm{~mL})$, reaction temperature $25^{\circ} \mathrm{C}$.

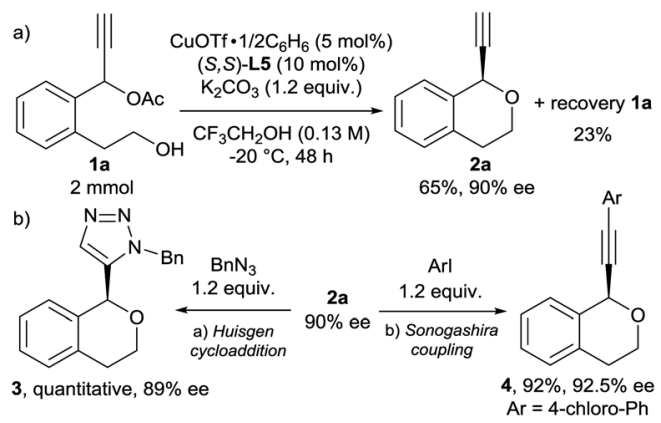

Scheme 2 Larger scale and diversified synthesis. Conditions: ${ }^{\mathrm{a}} 2 \mathrm{a}(0.23$ $\mathrm{mmol}), \mathrm{BnN}_{3}(0.25 \mathrm{mmol}), \mathrm{Cul}(10 \mathrm{~mol} \%), \operatorname{Pr}_{2} \mathrm{NEt}\left(2\right.$ equiv.), $\mathrm{THF}, 45^{\circ} \mathrm{C}$, 6 h. ${ }^{b} 2 a(0.24 \mathrm{mmol}), 1$-chloro-4-iodobenzene $(0.29 \mathrm{mmol})$, Cul (10 mol\%), $\mathrm{Pd}\left(\mathrm{PPh}_{3}\right)_{4}(5 \mathrm{~mol} \%), \mathrm{Et}_{3} \mathrm{~N}$ (4 equiv.) THF, rt, $16 \mathrm{~h}$.

configuration of the chiral isochroman $2 \mathbf{l}$ is $R$ at the propargylic position. $^{18}$

Next, to get information on the reaction mechanism, we examined a relationship between the enantiomeric purity of L5 and that of 2a (Fig. 3). As shown in Fig. 3, we obtained a positive non-linear relationship between them. This result indicates that a dicopper-allenylidene species worked as a key reactive intermediate in the present reaction system, as the similar phenomena as we observed in our previous reaction systems. ${ }^{15}$

On the basis of the experimental results described in this paper and our previous studies, a proposed reaction pathway for the enantioselective intramolecular etherification is shown in Scheme 3a. At first, dicopper-acetylide complex (A)

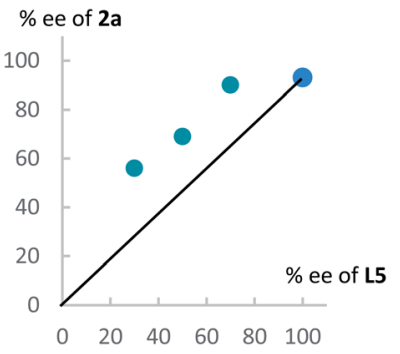

Fig. 3 Nonlinear relationship between the enantiopurity of L5 and 2a.

is formed from the dicopper complex and $\mathbf{1}$ in the presence of $\mathrm{K}_{2} \mathrm{CO}_{3}$ as a base. Then, dicopper-acetylide complex (B) may be formed by the elimination of acetate anion from $\mathbf{A}$. Next, enantioselective intramolecular nucleophilic attack by alcohol moiety occurs to afford the corresponding dicopperacetylide complex (C). Deprotonation of complex $\mathbf{C}$ occurs under the base condition to generate complex (D). Finally, complex $\mathbf{D}$ is converted into the starting complex $\mathbf{A}$ by the ligand exchange with another substrate 1 together with the formation of propargylic ether 2 as a product.

To account for the enantioselective formation of propargylic ethers, we have proposed a transition state involving the dicopper-acetylide complex as shown in Scheme $3 \mathrm{~b}$. The absolute configuration at the propargylic position in 2 indicates that the attack of alcohol on the cationic $\gamma$-carbon in the dicopper-acetylide complex occurs from the $S i$ face to the dicopper-acetylide ligand.

Based on results of optimisation, we believe that $\mathrm{CF}_{3}$ $\mathrm{CH}_{2} \mathrm{OH}$ solvent plays a critical role to achieve the high enantioselectivity in present reaction system. Schepp and coworkers found that the use of $\mathrm{CF}_{3} \mathrm{CH}_{2} \mathrm{OH}$ as solvent stabilised the allylic cation. ${ }^{19 a}$ In their report, the rate of nucleophilic attack to allylic cations slowed down with increasing of the concentration of $\mathrm{CF}_{3} \mathrm{CH}_{2} \mathrm{OH} .{ }^{19}$ As a result, we consider that a similar propargylic cation stabilisation might occur

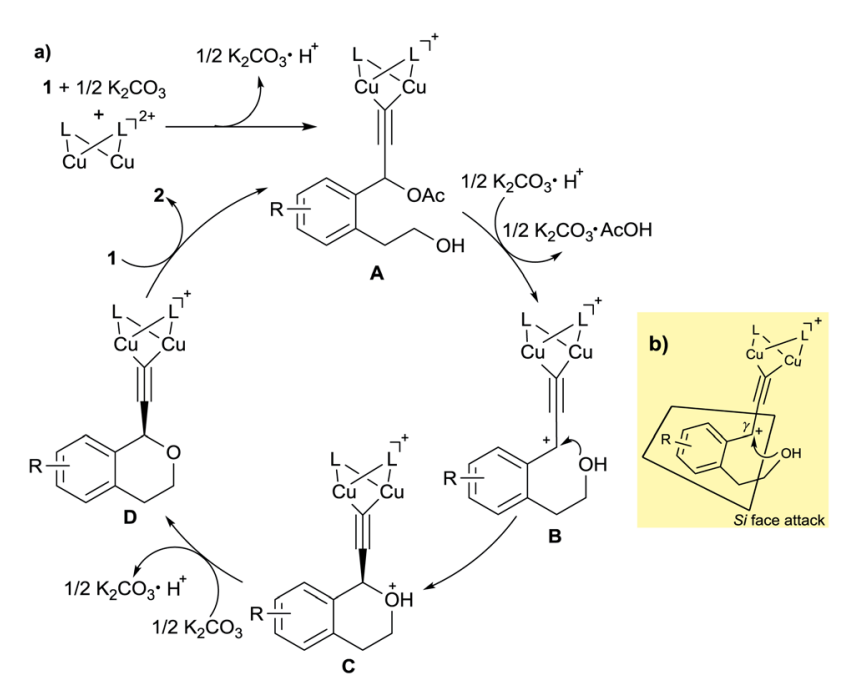

Scheme 3 Proposed reaction pathway and transition state of dicopper-acetylide complex. 
when $\mathrm{CF}_{3} \mathrm{CH}_{2} \mathrm{OH}$ is used as solvent in our present reaction system. We assume that the achievement of the high enantioselectivity in $\mathrm{CF}_{3} \mathrm{CH}_{2} \mathrm{OH}$ as solvent might relate to the lower reaction rate which results from the cation stabilisation. Further work is necessary to support our hypothesis.

Finally, for further application of enantioselective intramolecular etherification, we attempted the use of other types of substrates bearing different lengths of carbon chains in the alcohol moiety. After the optimisation, reactions of 5 and 6 under the best reaction conditions only gave the corresponding 5-membered ring cyclic ethers as 1-ethynyl-1,3dihydroisobenzofuran (7) and 7-membered ring cyclic ethers as 1-ethynyl-1,3,4,5-tetrahydrobenzo[c] oxepine (8) in $36 \%$ yield with $68 \%$ ee and $40 \%$ yield with $29 \%$ ee, respectively (eqn (1) and (2)). Separately, we confirmed that no reactions proceeded in $\mathrm{CF}_{3} \mathrm{CH}_{2} \mathrm{OH}$ as solvent. These experimental results are in sharp contrast to the enantioselective intramolecular 6-membered etherification (vide supra). Although the exact reason why the formation of 5- or 7membered ring cyclic ethers proceeded with a low to moderate reaction rate and enantioselectivity is not so clear, we assume that it may attribute to the very delicate relationship between the lengths of carbon chains in the alcohol moiety and the protic solvent at the enantio-determining step, where 6-membered ring cyclic ethers are well-matched and 5- or 7-membered ring cyclic ethers are mismatched.
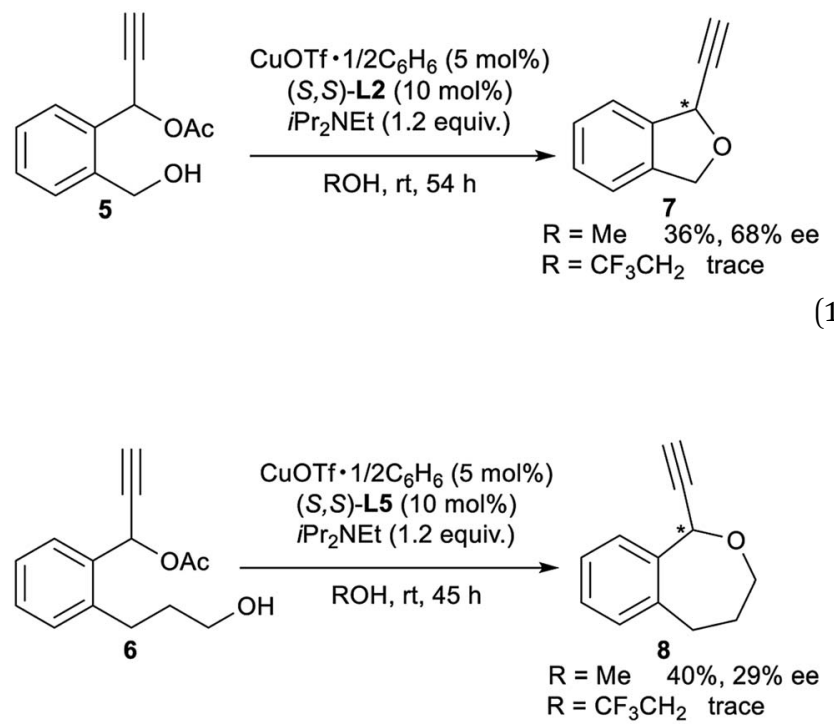

In summary, we have successfully established a coppercatalysed enantioselective intramolecular propargylic etherification of propargylic acetates with alcohols to give the corresponding 6-membered ring cyclic ethers in good yields with a high enantioselectivity. We believe that this is the first successful example of the enantioselective formation of chiral isochromans bearing a terminal alkyne moiety. Further exploration by using current strategy is currently now in progress.

\section{Conflicts of interest}

There are no conflicts to declare.

\section{Acknowledgements}

The work is supported by CREST, JST (JPMJCR1541). We thank Grants-in-Aid for Scientific Research (No. JP17H01201, JP15H05798, and JP18K19093) from JSPS and MEXT. S. L. is a recipient of the JSPS Predoctoral Fellowships for Young Scientists.

\section{Notes and references}

1 (a) J. Ralph, J. Peng and F. Lua, Tetrahedron Lett., 1998, 39, 4963-4964; (b) G. He, H. Matsuura, T. Takushi, S. Kawano and T. Yoshihara, J. Nat. Prod., 2004, 67, 1084-1087.

2 (a) M. P. DeNinno, R. Schoenleber, K. E. Asin, R. MacKenzie and J. W. Kebabian, J. Med. Chem., 1990, 33, 2948-2950; (b) K. Trisuwan, V. Rukachaisirikul, Y. Sukpondma, S. Phongpaichit, S. Preedanon and J. Sakayaroj, Tetrahedron, 2010, 66, 4484-4489.

3 E. L. Larghi and T. S. Kaufman, Synthesis, 2006, 187-220.

4 S. E. Reisman, A. G. Doyle and E. N. Jacobsen, J. Am. Chem. Soc., 2008, 130, 7198-7199.

5 For selected examples on asymmetric catalysis via oxocarbenium ions, see: (a) I. Coric, S. Vellalath and B. List, J. Am. Chem. Soc., 2010, 132, 8536-8537; (b) Z. Sun, G. A. Winschel, A. Borovika and P. Nagorny, J. Am. Chem. Soc., 2012, 134, 8074-8077; (c) K. Brak and E. N. Jacobsen, Angew. Chem., Int. Ed., 2013, 52, 534-561; (d) G. C. Tsui, L. Liu and B. List, Angew. Chem., Int. Ed., 2015, 54, 77037706.

6 (a) P. Maity, H. D. Srinivas and M. P. Watson, J. Am. Chem. Soc., 2011, 133, 17142-17145; (b) S. Dasgupta, T. Rivas and M. P. Watson, Angew. Chem., Int. Ed., 2015, 54, 14154-14158.

7 (a) Z. Meng, S. Sun, H. Yuan, H. Lou and L. Liu, Angew. Chem., Int. Ed., 2014, 53, 543-547; (b) M. Wan, S. Sun, Y. Li and L. Liu, Angew. Chem., Int. Ed., 2017, 56, 5116-5120; (c) Y. Li, M. Wan, S. Sun, Z. Fu, H. Huang and L. Liu, Org. Chem. Front., 2018, 5, 1280-1283.

8 S. Das, L. Liu, Y. Zheng, M. W. Alachraf, W. Thiel, C. K. De and B. List, J. Am. Chem. Soc., 2016, 138, 9429-9432.

9 For selected enantioselective $\mathrm{C}-\mathrm{O}$ bond formation reactions, see: (a) G. Zhong, Angew. Chem., Int. Ed., 2003, 42, 4247-4250; (b) C. Shu and J. F. Hartwig, Angew. Chem., Int. Ed., 2004, 43, 4794-4797; (c) S. F. Kirsch and L. E. Overman, J. Am. Chem. Soc., 2005, 127, 2866-2867; for reviews on enantioselective C-O bond formation, see: (d) C. F. Nising and S. Braese, Chem. Soc. Rev., 2008, 37, 1218-1228; (e) C. F. Nising and S. Braese, Chem. Soc. Rev., 2012, 41, 988-999.

10 (a) K. Miyata, H. Kutsuna, S. Kawakami and M. Kitamura, Angew. Chem., Int. Ed., 2011, 50, 4649-4653; (b) K. Miyata and M. Kitamura, Synthesis, 2012, 2138-2146.

11 S. E. Ammann, W. Liu and M. C. White, Angew. Chem., Int. Ed., 2016, 55, 9571-9575. 
12 (a) L. Bradsma, Preparative Acetylene Chemistry, Elsevier, Amsterdam, 2nd edn, 1988; (b) P. J. Stang and F. Diederich, Modern acetylene chemistry, John Wiley \& Sons, 2008; (c) P. G. Cozzi, R. Hilgraf and N. Zimmermann, Eur. J. Org. Chem., 2004, 4095-4105.

13 For enantioselective propargylic substitution reviews, see: (a) Y. Nishibayashi, Synthesis, 2012, 489-503; (b) D.-Y. Zhang and X.-P. Hu, Tetrahedron Lett., 2015, 56, 283-295; (c) k. Sakata and Y. Nishibayashi, Catal. Sci. Technol., 2018, 8, 12-25.

14 For selected recent copper-catalysed enantioselective propargylic substitution reactions, see: (a) R.-Z. Li, H. Tang, K.-R. Yang, L.-Q. Wan, X. Zhang, J. Liu, Z. Fu and D.-W. Niu, Angew. Chem., Int. Ed., 2017, 56, 7213-7217; (b) R.-Z. Li, H. Tang, L. Wan, X. Zhang, Z. Fu, J. Liu, S. Yang, D. Jia and D.-W. Niu, Chem, 2017, 3, 834-845; (c) K. Zhang, L.-Q. Lu, S. Yao, J.-R. Chen, D.-Q. Shi and W.-J. Xiao, J. Am.
Chem. Soc., 2017, 139, 12847-12854; (d) Z. Fu, N. Deng, S. N. Su, H. Li, R. Z. Li, X. Zhang, J. Liu and D.-W. Niu, Angew. Chem., Int. Ed., 2018, 57, 15217-15221; (e) J. E. Gómez, A. Cristofol and A. W. Kleij, Angew. Chem., Int. Ed., 2019, 58, 3903-3907.

15 K. Nakajima, M. Shibata and Y. Nishibayashi, J. Am. Chem. Soc., 2015, 137, 2472-2475.

16 H. C. Kolb, M. Finn and K. B. Sharpless, Angew. Chem., Int. Ed., 2001, 40, 2004-2021.

17 K. Sonogashira, Metal-Catalyzed Cross-Coupling Reactions, 1998, pp. 203-229.

18 See the ESI $\dagger$ in details.

19 (a) G. Hallett-Tapleya, F. L. Cozensa and N. P. Schepp, J. Phys. Org. Chem., 2009, 22, 343-348; a similar benzylic cation stabilisation by 1,1,1,3,3,3-hexafluoroisopropanol, see: (b) J. Ammer and H. Mayr, J. Phys. Org. Chem., 2013, 26, 59-63. 